\title{
USE OF SYNCHROTRON DIFFRACTION DATA FOR DESCRIBING CRYSTAL STRUCTURE AND CRYSTALLOGRAPHIC PHASE ANALYSIS OF R-PHASE NiTi SHAPE MEMORY ALLOY
}

\author{
HUSIN SITEPU* \\ Institut Laue-Langevin, BP 156, 38042 Grenoble Cedex 9, France
}

(Received 13 September 2003)

\begin{abstract}
Sitepu et al. (Sitepu, H., Schmahl, W.W., Khalil Allafi, J., Eggeler, G., Dlouhy, A., Reinecke, T., Brokmeier, H.G., Tovar M. and Többens, D.M. (2002b). Texture and quantitative phase analysis of aged Ni-rich NiTi using X-ray and neutron diffractions. Materials Science Forum, 394-395, 237-240.) showed that Rietveld refinement with generalized spherical harmonic (GSH) description for neutron powder diffraction (ND) data of the aged $(673 \mathrm{~K}, 20 \mathrm{~h}) \mathrm{Ni}$-rich NiTi shape memory alloy (Sitepu H. (2002). Assessment of preferred orientation with neutron powder diffraction data. J. Appl. Cryst, 35, 274-277); of nominal composition 50.7 at. $\% \mathrm{Ni}$ at $294 \mathrm{~K}$ consists of four phases: precipitate $\left(\mathrm{Ni}_{4} \mathrm{Ti}_{3}\right)$, R-phase, monoclinic (B19') and some residual cubic (B2). Therefore, they concluded that the differential scanning calorimetry (DSC) first peak, on cooling, $(321 \mathrm{~K})$ is not due to the formation of the R-phase alone. The second, lower DSC peak $(271 \mathrm{~K})$ is due to the transformation of R-phase and residual B2 phase to B19' phase. The structural refinement of R-phase problem, which was neglected in the previous study, was undertaken with great care in this study. The objective of the present article is to use the third generation synchrotron X-ray source at the European Synchrotron Research Facility (ESRF) in Grenoble, which make available X-ray beams of higher energy and much higher intensity than laboratory X-ray sources, for describing crystal structure of the R-phase in 50.75 at. $\%$ Ti- 47.75 at. $\% \mathrm{Ni}-1.50$ at. $\%$ Fe ternary alloy. The synchrotron diffraction data of R-phase were analyzed using the Rietveld refinement with GSH description. The results showed that no significant improvement in fit is found when the inversion center is removed from the $P \overline{3}$ model, suggesting that the space group is indeed $P \overline{3}$ and not $P 3$.
\end{abstract}

Keywords: Synchrotron diffraction; R-phase NiTi shape memory alloy; Generalized spherical harmonic; Rietveld refinement

\section{INTRODUCTION}

The most successful shape memory materials at present are NiTi shape memory alloys (SMAs) because they combine excellent functional properties (e.g. one way effect and superelasticity) with very good mechanical strength and ductility (Otsuka and Wayman, 1998). Moreover, NiTi SMAs exhibit good corrosion resistance that is important in medical application. Also, they have high specific electric resistance which allows the

*Fax: +3347620 7648. E-mail: sitepu@ill.fr 
alloys to be easily heated using an electric current. It occurs in simple system from high-temperature cubic (B2) austenitic phase structure to a monoclinic (B19') lowtemperature phase, with the trigonal R-phase occurring in an intermediate temperature range, depending on the thermomechanical history of the alloy, see Fig. 1. Since the R-phase transformation exhibits a small temperature hysteresis (i.e. 1-2 K), it has been mostly used for the practical applications of the NiTi SMAs. Several techniques have been used to produce the polycrystalline R-phase transformation such as work hardening followed by annealing, precipitation-hardening and the addition of the third element such as $\mathrm{Fe}$ and $\mathrm{Al}$. However, it was shown that a small addition of $\mathrm{Fe}$ separate the temperature ranges for $\mathrm{B} 2 \rightarrow \mathrm{R}$ and $\mathrm{B} 2 \rightarrow \mathrm{B} 19^{\prime}$ transformation by more than $100 \mathrm{~K}$. The R-phase transformation is first order and, therefore, a prominent change in the crystal structure should take place below a definite starting R-phase $\left(\mathrm{R}_{\mathrm{s}}\right)$ transformation temperature.

The R-phase transformation in NiTi SMA has been widely used in both the industrial and fundamental research because this alloy not only has shape memory effect or superelasticity but also small thermal hysteresis which is very useful for actuators applications. Therefore, the crystal structure of R-phase has been determined by various research

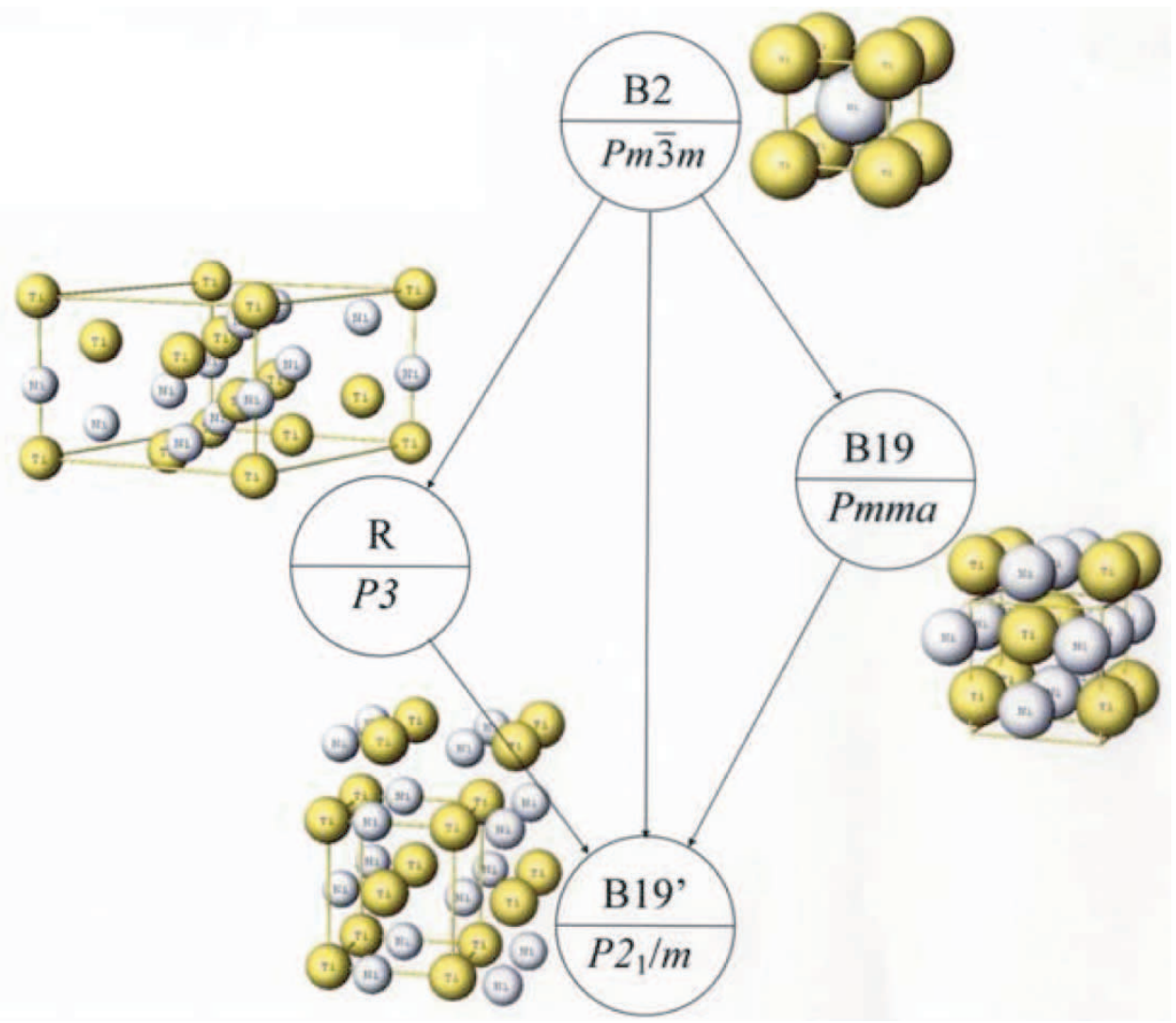

FIGURE 1 The martensitic transformations from parent B2-phase to R-phase in NiTi-based alloys. The $\mathrm{R}$-phase transformation in $\mathrm{Ti}-\mathrm{Ni}-\mathrm{Fe}$ alloys or in the aged $\mathrm{Ti}-\mathrm{Ni}$ alloys have attracted many researchers because of the curious transformation behavior and actuator applications due to small temperatures hysteresis. 
groups using X-ray powder diffraction (XRD) and electron diffraction data (Hara et al., 1995, 1997; and references therein) and showed that the space group of the R-phase is $P 3$. However, the precision of the results derived from Rietveld refinements for various XRD data set of the R-phase in 50.75 at. \% Ti-47.75 at. \% Ni-1.50 at.\% Fe alloy reported by Hara et al. (1995) needs further special attention because the sample investigated has fiber texture which had not been corrected. Subsequently, the crystal structure of the same material was determined by Schryvers and Potapov (2002) using electron diffraction data which showed that the atoms in the R-phase structure are located in centrosymetric positions leading to $P \overline{3}$ space group instead of the $P 3$.

It is possible to extract texture information from such XRD and neutron powder diffraction (ND) data if the pattern for a randomly oriented specimen can be modeled, or simulated, from knowledge of the crystal structure parameters and various other factors (e.g. line broadening and anisotropic strain parameters) which influence the pattern. The pertinent attribute of neutrons with respect to texture is the small absorption coefficients of neutrons for most materials, compared to X-rays. However, ND is characterized by relatively low intensities giving rise to slow rates of data acquisition and a special resolution. In the present study the third generation synchrotron X-ray sources at the European Synchrotron Research Facility (ESRF) in Grenoble, which make available X-ray beams of higher energy and much higher intensity than laboratory X-ray sources, has been used for describing the crystal structure of the same R-phase material used by the above authors. The chief virtue of the synchrotron source is the combination of substantial penetration with high intensity and high spatial and angular resolution, which gives fast data acquisition rates. It is noted that, the texture correction and minor cubic phase problems which were neglected by Hara et al. were undertaken with great care in this study (see below).

Since it is quite difficult to grow up a single crystal of the R-phase, preferred crystallographic orientation, i.e. texture has become a critical importance aspect of contemporary XRD analysis, as the effect is present in this technologically important polycrystalline NiTi SMA. Therefore, if the effect is ignored or is modeled incorrectly in Rietveld refinement of powder diffraction data, it can cause serious systematic errors not only in quantitative phase analysis but also in crystal structure determination. Fortunately, texture correction has been a part of the Rietveld refinement technique ever since the initial description of the method by Rietveld (1969), who used a simple Gaussian model for grain orientations in ND samples. Subsequently, simple onedimensional correction approaches, based on the March (1932) model of platy or fibrous particles (Dollase, 1986), are often inadequate as was demonstrated by Choi et al. (1993). The GSH method (Bunge, 1982) of the orientation distribution function (ODF), which maps the probability of each of the possible grain orientations with respect to the external sample dimensions, has been recommended and/or used successfully by different authors in the Rietveld refinement (Popa, 1992; Ferrarri and Lutterrotti, 1994; Von Dreele, 1997). An analog scheme that relies on the WIMV method of the ODF, which is an iterative direct algorithm with well developed ghost corrections, has been implemented into Rietveld MAUD program and successfully used by Lutterotti et al. (1997).

Sitepu (2002) used the GSAS (Larson and Von Dreele, 2000) Rietveld program, in which the generalized spherical harmonic $(\mathrm{GSH})$ is generated using selection rules depending on the crystal symmetry of the phase under investigation (Popa, 1992; Von Dreele, 1997), and showed that for texture in ND data, the correct crystal structure 
can be obtained when applying correction to intensities using the GSH description. For unknown structures, it is possible to get correct structure parameters in textured samples from ND pattern, but one also must determine the texture along with the structure. If the texture of the sample is important, it is possible to refine correct structural parameters of ND data set only if the texture can be approximated by a model with cylindrical symmetry with respect to the ND pattern. Further work should be undertaken with great care and accuracy to determine whether this is always the case. Subsequently, Sitepu et al. (2002a,b) investigated the transformation of a Ni-rich $\mathrm{NiTi}$ alloy of nominal composition $50.7 \mathrm{at} \% \mathrm{Ni}$ which was solution annealed, water quenched and aged $(673 \mathrm{~K}, 20 \mathrm{~h})$ using differential scanning calorimetry (DSC), transmission electron microscopy (TEM), XRD and ND. The material shows a two-step transition on cooling with DSC peaks at 321 and $271 \mathrm{~K}$ while on heating, a single DSC peak occurs at $329 \mathrm{~K}$ (see Fig. 2). The results derived from Rietveld refinement with GSH description for ND data showed that the aging leads to the formation of $\mathrm{Ni}_{4} \mathrm{Ti}_{3}$ precipitates in the microstructure, and in the presence of the precipitates the martensitic transformation occurs from the cubic B2-phase via the R-phase to B19' martensite. However, the first peak on cooling is not due to the formation of $\mathrm{R}$-phase alone. Below the peak temperature, R-phase is present along with some B19' and with residual B2 and the precipitates. The second peak is related to the transformation of R-phase and B2 to B19'.

The study reported in this article seeks to extend the work of Sitepu (2002) and Sitepu et al. $(2002 \mathrm{a}, \mathrm{b})$ on the general applicability of GSH formulation for correcting texture with the R-phase in 50.75 at.\% Ti-47.75at.\% Ni-1.50at.\% Fe alloy synchrotron high resolution powder diffraction data, with reference to: (i) the reliability of the formulation; (ii) its use in correcting intensities for texture bias and (iii) refine more accurately the atomic positions and to clarify the controversy in the determination of R-phase space group.

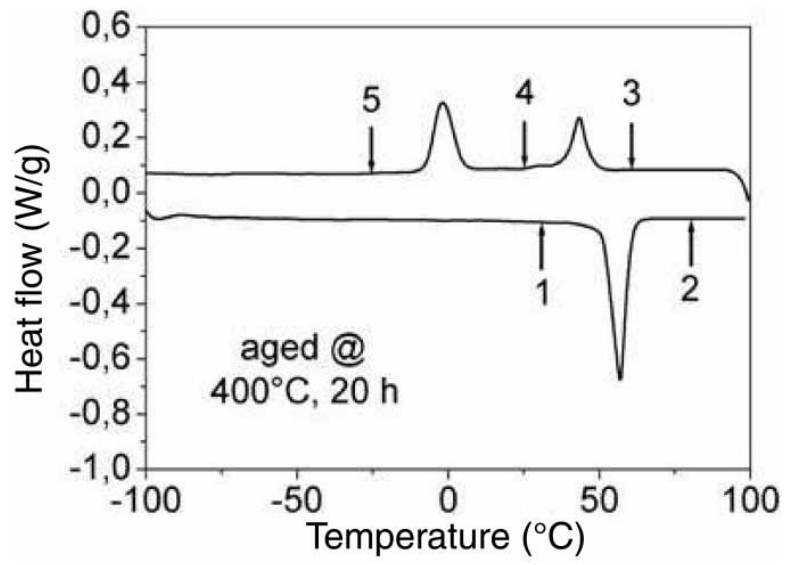

FIGURE 2 The differential scanning calorimetry curve for the aged Ni-rich NiTi SMA which shows a two step transformation on cooling from B2 $\rightarrow \mathrm{R} \rightarrow \mathrm{B} 19^{\prime}$, and a one step transformations on heating B19' $\rightarrow$ B2. The five arrows indicate temperatures where the data were measured using XRD and ND. On cooling, the R-phase and B19' phase are present after the first release of latent heat (see arrow number 4). This is due to a heterogeneous microstructure after solution annealing and ageing (Sitepu et al., 2002a,b). 


\section{EXPERIMENTAL AND RIETVELD REFINEMENT RESULTS}

In this study, the wire specimen with a diameter of $10 \mathrm{~mm}$ and $30 \mathrm{~mm}$ height and with the composition of a 50.75 at. \% Ti-47.75 at. \% Ni-1.50 at. \% Fe ternary alloy was used. This rod ternary alloy was produced by the Tokin Corperation and provided by Professors T. Hara, T. Ohba to Professor Schryvers for R-phase structure refinement using electron diffraction data (Schryvers and Potapov, 2002). Then, the sample was sent to the author. The details of the alloy preparation and heat treatment are fully described by Hara et al. $(1995,1997)$ and the DSC curve is given in Fig. 3. It was noted, that the wire-shaped $\mathrm{Ti}-\mathrm{Ni}$ alloy has a fiber texture of $\langle 111\rangle_{\mathrm{B} 2}$. While the fiber texture information proved to be useful information as a qualitative measure of texture at this ternary alloy, the texture information were not used by Hara et al. $(1995,1997)$ to quantify texture or to correct the intensities due to the effects of texture.

Synchrotron diffraction data of the NiTi rod with the $10 \mathrm{~mm}$ in diameter were collected using the ID31 high resolution powder diffractometer at the ESRF in Grenoble, France with the energy of $60 \mathrm{keV}(\lambda=0.2069 \AA)$. During the data collection the instrument was equipped with a cryostream cold-nitrogen-gas blower to heat and cool the alloy with a temperature constant zone exceeding the length of the rod alloy. After introducing the alloy in the diffractometer it was then slowly and carefully heated up to $373 \mathrm{~K}$. Then, the sample was held for $360 \mathrm{~s}$ to reach thermal equilibrium. The temperature was then slowly cooled down to $303 \mathrm{~K}$ and held for $360 \mathrm{~s}$. Then, the first data was collected. Hold periods for $360 \mathrm{~s}$ were conducted to each of the sub-

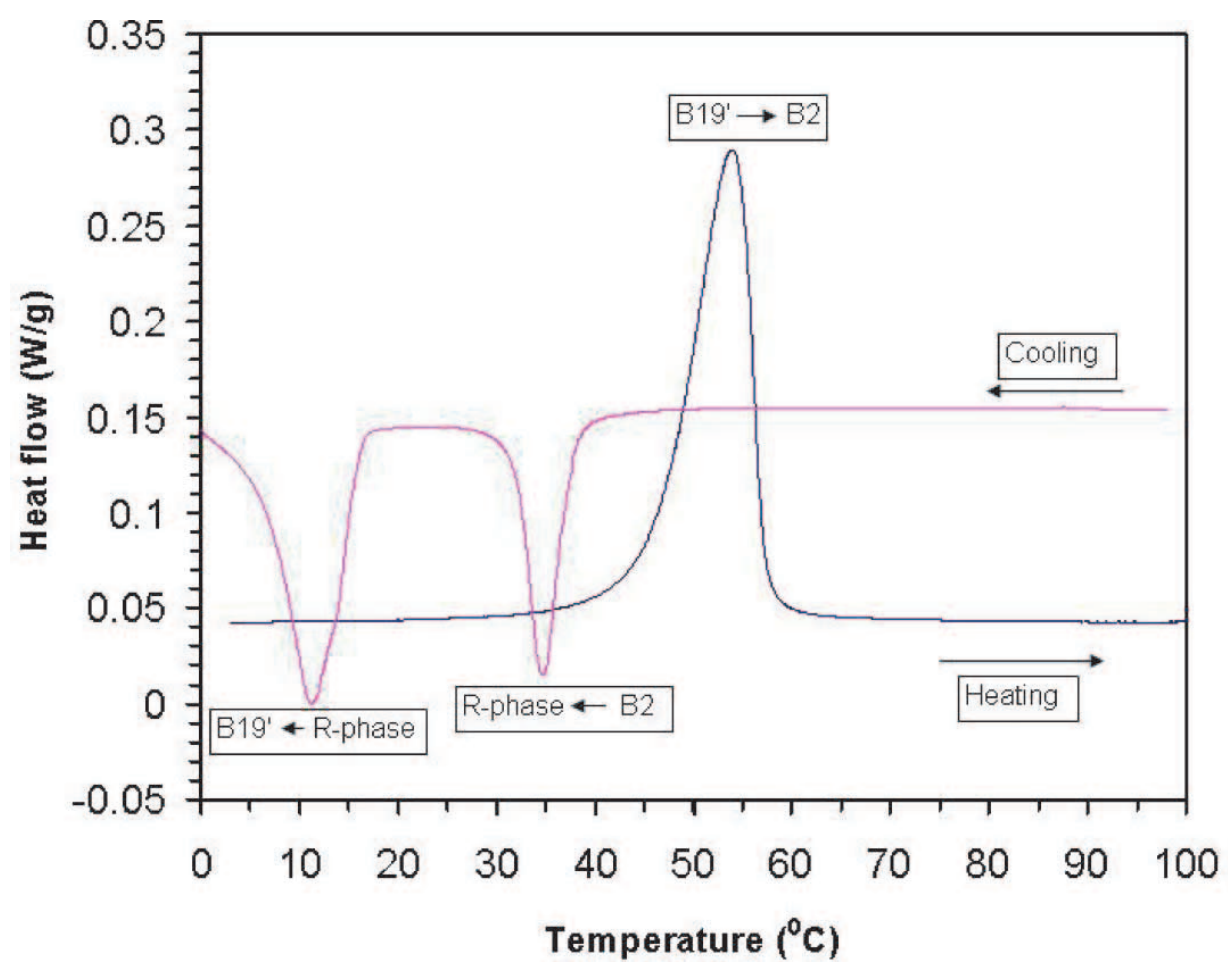

FIGURE 3 The differential scanning calorimetry curve for the polycrystalline R-phase in 50.75 at. $\%$ Ti-47.75 at. \% Ni-1.50 at. \% Fe alloy. 
sequent synchrotron diffraction data collection at temperatures of 301, 299, 297, 295, 293, 291 and $289 \mathrm{~K}$, on cooling (see Fig. 4 and Table III). The $2 \theta$ scan range was three scans from $2^{\circ}$ to $22^{\circ}$ each at a slightly rock in phi with a $2 \theta$ step size of $0.008^{\circ}$, and a total counting time of approximately $4 \mathrm{~h}$ for each temperature point. The data were then bin for each scan to yield a single histogram. Figure 4 depicts the $2 \theta$ Bragg between $5^{\circ}$ and $6^{\circ}$ of the R-phase, which shows that synchrotron X-ray beams provides very high intensity to background ratio.

The refinement strategy for all synchrotron data sets was similar to that described by Sitepu (2002), with the difference that in the present study, there is only GSH description was employed and reported. The structural parameters for R-phase in the trigonal description for both space groups $P 3$ and $P \overline{3}$ were described by Hara et al. (1997) and Schryvers and Potapov (2002), respectively. The parameters refined were: phase scale factor and the background component of the patterns with a 6-parameter Linear interpolation; lattice parameters; zero point $2 \theta_{0}$ (off-set in the $2 \theta$ scale of the goniometer); the Lorentzian and Gaussian terms of pseudo-Voigt profile function and anisotropic strain parameters (Popa, 1998; Stephens, 1999); structural parameters and thermal parameters; and texture. The default sample texture symmetry was chosen to be cylindrical in the Rietveld refinement with the GSH description; and the maximum of six harmonic orders was selected after preliminary calculations with eight and ten orders gave the same results. Summary of the Rietveld refinements for synchrotron data at a temperature of $297 \mathrm{~K}$ for both $P 3$ and $P \overline{3}$ space groups are given in Tables I and II, respectively. The values in parentheses in this and subsequent tables are estimated standard deviations obtained from the refinement. Figure 5 shows the agreement between the measured and calculated patterns when the GSH description was employed in the Rietveld refinement. The observed data are indicated by plus signs and the calcu-

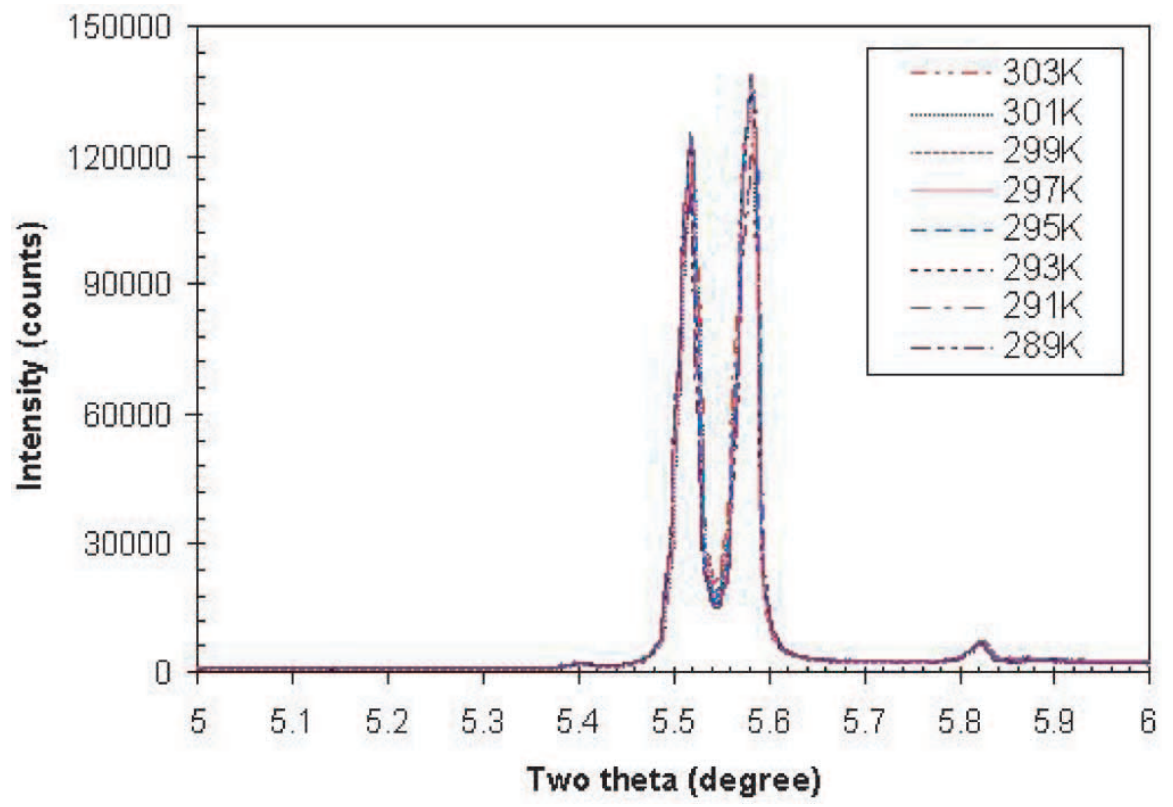

FIGURE 4 Various synchrotron high resolution powder diffraction data of R-phase in 50.75 at. $\%$ $\mathrm{Ti}-47.75$ at. \% Ni-1.50 at.\% Fe alloy, on cooling. 
TABLE I Crystal structure model for R-phase in the trigonal description for space group P3 (No 143). Unit cell parameters: $a=7.3472(2) \AA, c=5.2837(3) \AA$ and $\alpha=\beta=90^{\circ}$ and $\gamma=120^{\circ}$

\begin{tabular}{|c|c|c|c|c|c|}
\hline $\begin{array}{l}\text { Atomic } \\
\text { positions }\end{array}$ & $\begin{array}{l}\text { Wyckoff } \\
\text { code }\end{array}$ & $\begin{array}{c}\text { Refined } \\
\text { parameters }\end{array}$ & $\begin{array}{l}\text { This } \\
\text { work }\end{array}$ & $\begin{array}{c}\text { Hara } \\
\text { et al. }(1995)\end{array}$ & $\begin{array}{c}\text { Schryvers and } \\
\text { Potapov } \\
(2002)\end{array}$ \\
\hline $\operatorname{Ti1}(0,0,0)$ & $1(a)$ & $100 \times U_{\text {iso }} \AA^{2}$ & $1.304(6)$ & 1.013 & - \\
\hline $\operatorname{Ti} 2(1 / 3,2 / 3, z)$ & $1(b)$ & $\begin{array}{l}z \\
100 \times U_{\text {iso }} \AA^{2}\end{array}$ & $\begin{array}{l}0.065(1) \\
1.304(6)\end{array}$ & $\begin{array}{l}0.084(3) \\
1.013\end{array}$ & -0.096 \\
\hline $\operatorname{Ti} 3(2 / 3,1 / 3, z)$ & $1(c)$ & $100 \times U_{\text {iso }} \AA^{2}$ & $\begin{array}{l}0.010(2) \\
1.304(6)\end{array}$ & $\begin{array}{l}0.009(3) \\
1.013\end{array}$ & $\begin{array}{c}-0.042 \\
-\end{array}$ \\
\hline $\operatorname{Ti} 4(x, y, z)$ & $3(d)$ & $\begin{array}{l}x \\
y \\
z \\
100 \times U_{\text {iso }} \AA^{2}\end{array}$ & $\begin{array}{r}0.343(1) \\
-0.004(4) \\
0.353(1) \\
0.911(1)\end{array}$ & $\begin{array}{c}0.335(1) \\
-0.004(7) \\
0.361(12) \\
1.013\end{array}$ & $\begin{array}{r}0.353 \\
-0.007 \\
0.303 \\
-\end{array}$ \\
\hline $\operatorname{Ti5}(x, y, z)$ & $3(d)$ & $\begin{array}{l}x \\
y \\
z \\
100 \times U_{\text {iso }} \AA^{2}\end{array}$ & $\begin{array}{l}0.674(1) \\
0.002(6) \\
0.668(1) \\
0.911(1)\end{array}$ & $\begin{array}{l}0.677(9) \\
0.010(6) \\
0.684(2) \\
1.013\end{array}$ & $\begin{array}{r}0.699 \\
-0.018 \\
0.617 \\
-\end{array}$ \\
\hline $\operatorname{Nil}(0,0, z)$ & $1(a)$ & $\begin{array}{l}z \\
100 \times U_{\text {iso }} \AA^{2}\end{array}$ & $\begin{array}{l}0.481(1) \\
0.263(5)\end{array}$ & $\begin{array}{l}0.457(2) \\
1.013\end{array}$ & $\begin{array}{l}0.514 \\
-\end{array}$ \\
\hline $\operatorname{Ni} 2(1 / 3,2 / 3, z)$ & $1(b)$ & $\begin{array}{l}z \\
100 \times U_{\text {iso }} \AA^{2}\end{array}$ & $\begin{array}{l}0.574(1) \\
0.263(5)\end{array}$ & $\begin{array}{l}0.541(1) \\
1.013\end{array}$ & $\begin{array}{l}0.441 \\
-\end{array}$ \\
\hline $\operatorname{Ni3}(2 / 3,1 / 3, z)$ & $1(c)$ & $z=0 \times U_{\text {iso }} \AA^{2}$ & $\begin{array}{l}0.459(1) \\
0.263(5)\end{array}$ & $\begin{array}{l}0.396(3) \\
1.013\end{array}$ & $\begin{array}{l}0.491 \\
-\end{array}$ \\
\hline $\mathrm{Ni} 4(x, y, z)$ & $3(d)$ & $\begin{array}{l}x \\
y \\
z \\
100 \times U_{\text {iso }} \AA^{2}\end{array}$ & $\begin{array}{r}0.334(4) \\
-0.014(3) \\
0.866(4) \\
0.141(8)\end{array}$ & $\begin{array}{c}0.318(8) \\
-0.022(6) \\
0.854(2) \\
1.013\end{array}$ & $\begin{array}{l}0.375 \\
0.010 \\
0.788 \\
-\end{array}$ \\
\hline $\operatorname{Ni5}(x, y, z)$ & $3(d)$ & $\begin{array}{l}x \\
y \\
z \\
100 \times U_{\text {iso }} \AA^{2}\end{array}$ & $\begin{array}{l}0.687(4) \\
0.019(4) \\
0.163(1) \\
0.141(8)\end{array}$ & $\begin{array}{l}0.688(6) \\
0.021(5) \\
0.160(2) \\
1.013\end{array}$ & $\begin{array}{l}0.680 \\
0.010 \\
0.112 \\
-\end{array}$ \\
\hline \multicolumn{2}{|c|}{ Weight percentage (wt\%) } & $\begin{array}{l}\text { R-phase } \\
\text { Cubic (B2) }\end{array}$ & $\begin{array}{r}94.318(2) \\
5.682(1)\end{array}$ & $\begin{array}{r}100.000 \\
0.000\end{array}$ & $\begin{array}{r}100.000 \\
0.000\end{array}$ \\
\hline
\end{tabular}

${ }^{1}$ Co-ordinates, $1(a)=0,0, z ; 1(b)=1 / 3,2 / 3, z ; 1(c)=2 / 3,1 / 3, z ; 3(d)=x, y, z$.

TABLE II Crystal structure model for R-phase in the trigonal description for space group $P \overline{3}$ (No. 147). Unit cell parameters: $a=7.3472(2) \AA, c=5.2837(3) \AA$ and $\alpha=\beta=90^{\circ}$ and $\gamma=120^{\circ}$

\begin{tabular}{|c|c|c|c|c|}
\hline Positions & Wyckoff code ${ }^{1}$ & $\begin{array}{c}\text { Refined } \\
\text { parameters }\end{array}$ & $\begin{array}{l}\text { This } \\
\text { work }\end{array}$ & $\begin{array}{l}\text { Schryver and } \\
\text { Popatov (2002) }\end{array}$ \\
\hline $\operatorname{Ti1}(0,0,0)$ & $1(a)$ & $100 \times U_{\text {iso }} \AA^{2}$ & $1.057(5)$ & - \\
\hline $\operatorname{Ti} 2(1 / 3,2 / 3, z)$ & $2(d)$ & $\begin{array}{l}z \\
100 \times U_{\text {iso }} \AA^{2}\end{array}$ & $\begin{array}{l}0.031(3) \\
1.057(5)\end{array}$ & $\begin{array}{l}0.045 \\
-\end{array}$ \\
\hline $\operatorname{Ti} 3(x, y, z)$ & $6(\mathrm{~g})$ & $\begin{array}{l}x \\
y \\
z \\
100 \times U_{\text {iso }} \AA^{2}\end{array}$ & $\begin{array}{r}0.332(4) \\
-0.007(2) \\
0.342(2) \\
1.057(5)\end{array}$ & $\begin{array}{r}0.346 \\
-0.002 \\
0.346 \\
-\end{array}$ \\
\hline $\operatorname{Nil}(0,0,0.5)$ & $1(b)$ & $100 \times U_{\text {iso }} \AA^{2}$ & $0.446(3)$ & - \\
\hline $\mathrm{Ni} 2(1 / 3,2 / 3, z)$ & $2(d)$ & $\begin{array}{l}z \\
100 \times U_{\text {iso }} \AA^{2}\end{array}$ & $\begin{array}{l}0.565(3) \\
0.446(3)\end{array}$ & $\begin{array}{l}0.547 \\
-\end{array}$ \\
\hline $\operatorname{Ni} 3(x, y, z)$ & $6(g)$ & $\begin{array}{l}x \\
y \\
z \\
100 \times U_{\text {iso }} \AA^{2}\end{array}$ & $\begin{array}{r}0.322(3) \\
-0.020(2) \\
0.854(2) \\
0.446(3)\end{array}$ & $\begin{array}{r}0.332 \\
-0.008 \\
0.815 \\
-\end{array}$ \\
\hline \multicolumn{2}{|c|}{ Weight percentage $(\mathrm{wt} \%)$} & $\begin{array}{l}\text { R-phase } \\
\text { Cubic (B2) }\end{array}$ & $\begin{array}{r}97.085(7) \\
2.915(3)\end{array}$ & $\begin{array}{r}100.000 \\
0.000\end{array}$ \\
\hline
\end{tabular}

${ }^{1}$ Co-ordinates, $1(b)=0,0,1 / 2 ; 2(d)=1 / 3,2 / 3, z ; 6(g)=x, y, z$. 
lated profile is the continuous line in the same field. The sets of vertical lines below the profiles represent the positions of all possible Bragg reflections. The lower plot is the difference between the measured and calculated patterns on the same scale as the measured and calculated patterns. Table III shows the figures-of-merit and goodness-of-fit index for all data set of single high resolution powder diffraction data. The texture index ranges from 1.2 to 1.3 multiples of a random distribution (mrd) for R-phase and from 2.7 to $2.8 \mathrm{mrd}$ for cubic phase. In the case of random orientation of the crystallites, the texture index is unity.

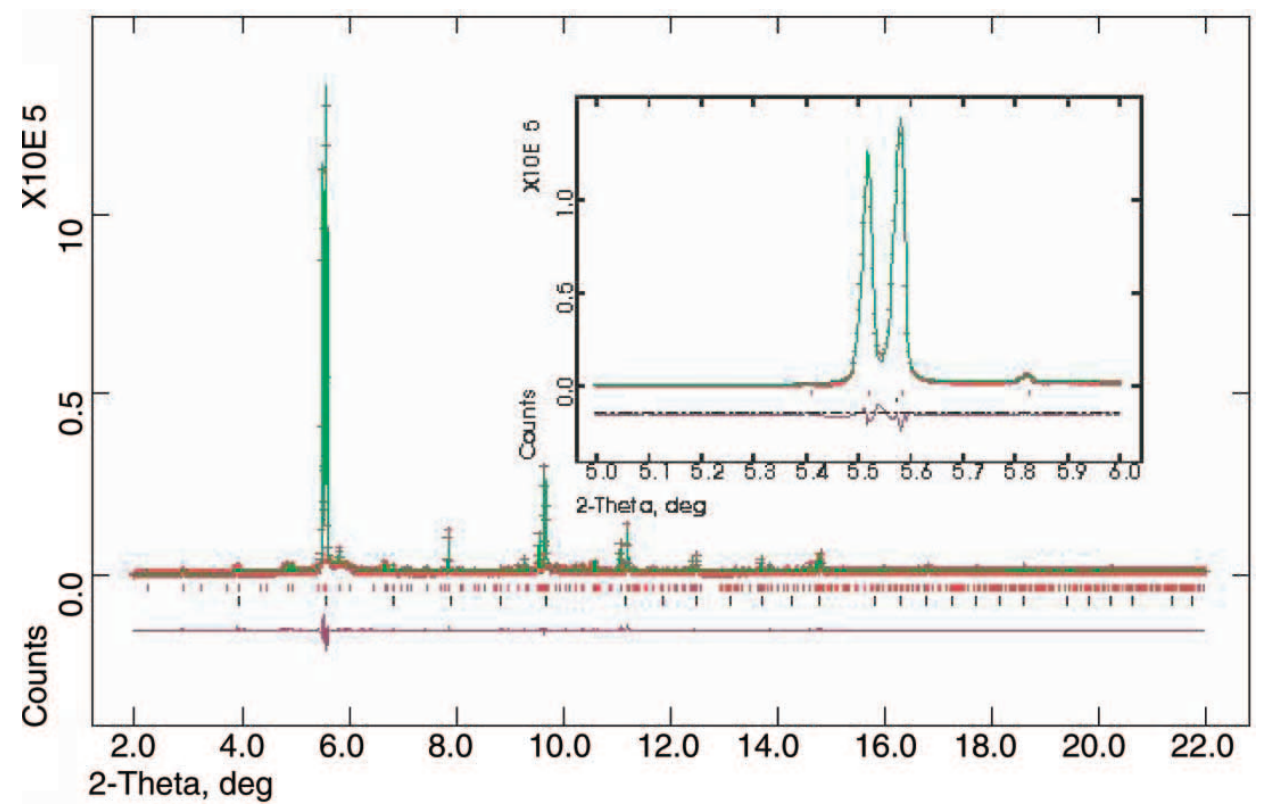

FIGURE 5 The agreement between measured and calculated synchrotron diffraction patterns for R-phase in 50.75 at. $\%$ Ti- 47.75 at. \% Ni-1.50 at. \% Fe ternary alloy collected at $297 \mathrm{~K}$, on cooling, following Rietveld refinement with the GSH description for texture.

TABLE III Summary of the Rietveld refinement results for R-phase sample

\begin{tabular}{|c|c|c|c|c|c|c|c|c|}
\hline \multirow{2}{*}{$\begin{array}{l}\text { Temp } \\
K\end{array}$} & \multicolumn{4}{|c|}{ P3 space group } & \multicolumn{4}{|c|}{$P \overline{3}$ space group } \\
\hline & $R_{P}$ & $R_{W P}$ & $R\left(F^{2}\right)$ & $\chi^{2}$ & $R_{P}$ & $R_{W P}$ & $R\left(F^{2}\right)$ & $\chi^{2}$ \\
\hline 303 & 4.89 & 6.82 & 11.42 & 6.83 & 5.03 & 7.09 & 10.27 & 7.37 \\
\hline 301 & 4.84 & 6.76 & 9.62 & 6.39 & 4.87 & 6.97 & 8.54 & 6.77 \\
\hline 299 & 4.85 & 6.97 & 10.10 & 6.36 & 5.06 & 7.10 & 9.30 & 6.24 \\
\hline 297 & 4.97 & 7.14 & 10.53 & 6.32 & 5.11 & 7.18 & 9.99 & 6.37 \\
\hline 295 & 4.81 & 6.12 & 9.33 & 5.90 & 5.02 & 7.13 & 8.60 & 5.89 \\
\hline 293 & 4.87 & 6.09 & 9.45 & 5.49 & 5.08 & 7.22 & 8.62 & 5.67 \\
\hline 291 & 4.86 & 7.11 & 9.26 & 5.19 & 5.07 & 7.26 & 8.80 & 5.37 \\
\hline 289 & 5.47 & 7.36 & 11.32 & 6.93 & 5.92 & 7.82 & 10.73 & 7.82 \\
\hline
\end{tabular}

The results reported by Hara et al. (1995) at a temperature of $297 \mathrm{~K}$

\begin{tabular}{llll}
297 & 6.10 & 8.19 & 24.02 \\
\hline
\end{tabular}




\section{DISCUSSION}

Tables I and II show the crystal structures for synchrotron diffraction data of R-phase at a temperature of $297 \mathrm{~K}$ when the $P 3$ and $P \overline{3}$ space groups were included in the Rietveld refinement with GSH description for texture correction. The anisotropic temperature factors, $\left[100 \times U_{\text {iso }} \AA^{2}\right]$, were not determined by Schryver and Potopov (2002). The corresponding values were fixed by Hara et al. $(1995,1997)$ at $1.013 \AA^{2}$ in the Rietveld refinement without texture correction for XRD data. It is noted, that the $P \overline{3}$ space group was not used by Hara et al. $(1995,1997)$ in the refinement (see Tables II and III). In the present study, the anisotropic temperature factors derived from Rietveld refinement with GSH are 1.304(6) for Ti and 0.263(5) for Ni when the $P 3$ space group was used. The corresponding values are 1.057(5) for Ti and 0.446(3) for Ni when the $P \overline{3}$ was used in the refinement.

Table I shows that the difference between $\operatorname{Ti1}(z)$ and $\operatorname{Ti2}(z)$ is $0.065 \mathrm{c}$ while that between $\operatorname{Til}(z)$ and $\operatorname{Ti3}(z)$ is $0.010 c$. The differences between $\operatorname{Ni1}(z)$ and $\operatorname{Ni2}(z)$ is $0.093 \mathrm{c}$ and that between $\mathrm{Ni1}(z)$ and $\mathrm{Ni3}(z)$ is $0.022 c$. These values are smaller than that of the corresponding values reported by Hara et al. (1995) and Schryver and Potopov (2002). It is noted that, the crystallographic figures-of-merits $R_{W P}$ and $R\left(F^{2}\right)$ reported by Hara et al. (1997) are higher than that of the present study. This is because Hara et al. (1997) firstly did not correct the intensities due to the effects of texture and secondly they did not include the residual B2 phase in their Rietveld refinement. The weight percentages $(\mathrm{wt} \%)$ of the residual $\mathrm{B} 2$ cubic phase derived from Rietveld refinement with GSH description are $5.682(1) \%$ for $P 3$ space group and $2.915(3) \%$ for $P \overline{3}$ space group (see Tables II and III and Fig. 5 for more details).

The present synchrotron X-ray diffraction results for $P \overline{3}$ space group (see Table II) show that the deviations from the positions in the parent B2 structure are $0.031 \mathrm{c}$ for $\mathrm{Ti} 2(z)$ and $0.009 c$ for $\mathrm{Ti} 3(z)$; while that for $\mathrm{Ni2}(z)$ and $\mathrm{Ni3}(z)$ are $0.065 c$ and $0.021 c$, respectively. Whereas the $\mathrm{Ti3}(z)$ and $\mathrm{Ni3}(z)$ stay at approximately the same $z$-positions as those in the B2 parent phase, the shift values for both Ti3 $(x, y)$ and Ni3 $(x, y)$ are very small. The present results show that the structure is centrosymmetric with the symmetry center located at $\operatorname{Til}(x, y, z)$ and $\operatorname{Ni1}(x, y, z)$. The present results agreed quite satisfactorily with electron diffraction results reported by Schryver and Potopov (2002). The crystallographic figures-of-merit, $R_{W P}$ and $R\left(F^{2}\right)$, derived from Rietveld refinement with GSH are 7.18 and 9.99, respectively (see Table III). Also, the weight percentages for both the R-phase and B2 minor phase are $97.085(7) \%$ and $2.915(3) \%$, respectively. The weight percentage of the minor B2 phase is approximately twice lower than that of the $P 3$ space group. It may be due to the fact that the $P 3$ space group, which has twice adjusted atomic parameters more than that of the $P \overline{3}$ space group, is not the correct space group for the sample investigated in the present study. It is noted that, the minor B2 phase was not noticed by the Schryver and Popatov (2002). The minor B19' martensite present in the matrix was detected by electron diffraction; however, the weight percentage was not numerically quantified.

Table III shows that the crystallographic figures-of-merit $\left(R_{P}, R_{W P}\right.$ and $\left.R\left(F^{2}\right)\right)$ and goodness-of-fit indices, $\chi^{2}$, derived from Rietveld refinement with GSH description for $P 3$ space group provides quite similar results to that of $P \overline{3}$ space group even though the number of atomic positions refined in the $P 3$ is twice higher than that of the $P \overline{3}$. It is clearly seen from Table III that the $R\left(F^{2}\right)$ derived from Rietveld refinement with the GSH description for synchrotron diffraction data at $297 \mathrm{~K}$ is 2.5 times smaller 
than the corresponding value reported by Hara et al. $(1995,1997)$. The generally lower $R\left(F^{2}\right)$ obtained in the present study clearly shows that the R-phase rod is textured and it has to be corrected in order to get accurate results. Moreover, the goodness-of-fit, $\chi^{2}$, indices for $P 3$ provides quite similar results to that of $P \overline{3}$. However, the number of atom positions refined in the later space group is 0.5 times smaller than that of the former one. Furthermore, the $P \overline{3}$ space group, which is a subgroup of $P 3$, is therefore selected as the most probable space group of R-phase alloy investigated in the present study. It is worth noting that, the GSH description has recently successfully been used to provide an effective texture correction for Rietveld refinement using synchrotron XRD data. This is because the GSH description consists of a number of adjustable parameters and it is realistic for texture correction. It is noted, though that, an examination of the covariance terms from the last cycles of least-squares refinement showed no significant correlation among any of the spherical-harmonic coefficients or between the spherical-harmonic coefficients and the other parameters in the refinements, consistent with the orthogonality properties of the GSH functions. Apparently, the GSH functions are also orthogonal to all the other functions such as - crystal structure, background, profile shape etc. used in the Rietveld refinement with GSH description.

It is noted that, the GSH description for all synchrotron X-ray data set of the NiTi rod is an excellent descriptor for intensities correction due to the effects of texture. Moreover, the Rietveld refinement with the GSH harmonic provides accurate results for both quantitative phase analysis and crystal structure refinements. If there are more adjustable parameters, the goodness-of-fit indices are usually smaller than that of the low adjustable parameters. However, this is not the case in the present study which is shown in Table III that the $P 3$ space group provides quite similar results to that of $P \overline{3}$ space group even though the number of atomic positions refined in latter space group is twice more than that of the former space group. Moreover, the weight percentages for the minor cubic phase for both the $P 3$ and $P \overline{3}$ space groups can be accurately determined by Rietveld refinement with the GSH description. Therefore, the method used in the present study is a useful tool to correct the intensities due to the effects of texture for describing crystallographic phase fraction and crystal structure determination of R-phase in 50.75 at. \% Ti-47.75 at.\% Ni-1.50 at.\% Fe ternary alloy.

\section{CONCLUDING REMARKS}

Tables I and II show that R-phase crystal structure result derived from Rietveld refinement with GSH description for synchrotron diffraction data agreed quite satisfactorily with that of the electron diffraction results determined by Schryver and Popatov (2002). The present study provides not only the accurate crystal structures but also the weight percentages for both major phase (R-phase) and minor phase (residual B2 phase). The crystallographic figures-of-merit, $R\left(F^{2}\right)$, reported by Hara et al. $(1995,1997)$ is 2.5 times higher than that of the corresponding value determined by Rietveld refinement with GSH description for synchrotron diffraction data. This clearly shows that the rod is textured and it has to be corrected in order to get accurate results (see Fig. 5 and Table III). Furthermore, Table III shows that the crystallographic goodness-offit, $\chi^{2}$, indices for $P 3$ space group provide quite similar results to that of $P \overline{3}$ space group even though the number of atom positions refined in the latter is 0.5 times smaller than that of the former one. Therefore, it can be concluded that: (i) for texture 
in synchrotron powder diffraction data sets of R-phase the accurate crystal structure can be obtained when applying correction to intensities using the GSH description, (ii) the sample consists of minor cubic phase and (iii) no significant improvement in fit is found when the inversion center is removed from the $P \overline{3}$ model, suggesting that the space group is indeed $P \overline{3}$ and not $P 3$.

\section{Acknowledgments}

The help of Professors Hara, Ohba and Schryvers for providing the R-phase material and for invaluable contributions in interpreting data is most greatly appreciated. Thanks to F. Fauth, J. Wright, D. Hughes and P. Webster for their help in conducting the experiment and interpreting data. Part of this work is performed in the frame work of ME306 projects. The author is grateful to comments from reviewers and the editor that helped to improve the manuscript.

\section{References}

Bunge, H.-J. (1982). Texture Analysis in Materials Science: Mathematical Methods; translated by P.R. Morris. Butterworths, London.

Choi, C.S., Baker, E.F. and Orosz, J. (1993). Application of ODF to the Rietveld profile refinement of polycrystalline solid. Adv. X-ray Analysis, 37, 49-57.

Dollase, W.A. (1986). Correction of intensities for preferred orientation in powder diffractometry: application of the March model. J. Appl. Crys, 19, 267-272.

Ferrari, M. and Lutterrotti, L. (1994). Method for simultaneous determination of anisotropic residual stresses and texture by X-ray diffraction. J. Appl. Phys, 76, 7246-7255.

Hara, T., Ohba, T., Okunishi, E. and Otsuka, K. (1997). Structural study of R-phase in Ti-50.75 at. \% and Ti-47.75at. $\%$ Ni-1.50at.\%Fe alloys. Mater. Trans. JIM, 38, 11-17.

Hara, T., Ohba, T. and Otsuka, K. (1995). Structural study of the R-phase in Ti-Ni alloy by the Rietveld method. J. de Physique III, 5, 641-645.

Larson, A.C. and Von Dreele, R.B. (2000) General Structure Analysis System (GSAS), 86-748. Los Alamos National Laboratory, Report LAUR.

Lutterotti, L., Matthies, S., Wenk, H.-R., Schultz, A.S. and Richardson Jr., J.W. (1997). Combined texture and structure analysis of deformed limestone from time-of-flight neutron diffraction spectra. J. Appl. Phys. 81, 594-600.

March, A. (1932). Mathematische Theorie der Regelung nach der Korngestalt bei affiner Deformation. Z. Kristallogr, 81, 285-297.

Otsuka, K. and Wayman, C.M. (1998) Shape Memory Materials. Cambridge University Press, Cambridge.

Popa, N.C. (1992). Texture in Rietveld refinement. J. Appl. Cryst, 25, 611-616.

Popa, N.C. (1998). The (hkl) dependence of diffraction-line broadening caused by strain and size for all Laue groups in Rietveld refinement. J. Appl. Cryst, 31, 176-180.

Rietveld, H.M. (1969). A profile refinement method for nuclear and magnetic structures. J. Appl. Cryst, 2 , $65-71$.

Schryvers, D. and Potapov, P.L. (2002). R-phase structure refinement using electron diffraction data. Materials Trans, 43(5), 774-779.

Sitepu H. (2002). Assessment of preferred orientation with neutron powder diffraction data. J. Appl. Cryst, 35, $274-277$.

Sitepu, H., Schmahl, W.W., Khalil Allafi, J., Eggeler, G., Dlouhy, A., Reinecke, T., Brokmeier, H.G., Tovar M. and Többens, D.M. (2002b). Texture and quantitative phase analysis of aged Ni-rich NiTi using X-ray and neutron diffractions. Materials Science Forum, 394-395, 237-240.

Sitepu, H., Schmahl, W.W., Khalil Allafi, J., Eggeler, G., Dlouhy, A., Többens, D.M. and Tovar M. (2002a). Neutron diffraction phase analysis during thermal cycling of a Ni-rich NiTi shape memory alloy using the Rietveld method. Scripta Mater, 46, 543-548.

Stephens, P.W. (1999). Phenomenological model of anisotropic peak broadening in powder diffraction. J. Appl. Cryst, 32, 281-289.

Von Dreele, R.B. (1997). Quantitative texture analysis by Rietveld refinement. J. Appl. Cryst, 30, 517-525. 